\title{
Developing an Inventory Mathematical Model with Deterioration Variables for Discounted Stochastic Goods
}

\author{
Mohammad Reza Shahraki*, Alireza Shahraki and Navid Javdan \\ Department of Industrial Engineering, University of Sistan and Baluchestan; mr.shahraki@eng.usb.ac.ir, \\ shahrakiar@hamoon.usb.ac.ir, javdan.navid@pgs.usb.ac.ir
}

\begin{abstract}
Experts believe that a large percentage of total corporate capitals lie in organizational inventories. Therefore, a more thorough and intelligent review of the inventory issue empowers organizations to optimally make use of all their resources to achieve better efficiency and effectiveness. This might, in turn, help organizations in reaching their goals. In this study, an inventory model under general discount and stochastic deteriorating conditions is developed. Deterioration was studied as a Stochastic variable while other variables were deterministic. The objective of this study was to reduce the expected cost of the whole system. First, the reorder point was determined by the EOQ model, and then other price cut points (due to discount or inventory Deterioration) were determined. Finally, the total cost of the system was computed for all points, by which the reorder point had the lowest cost. The developed model was further analyzed through a numerical example.
\end{abstract}

Keywords: Inventory; Deterioration; Discount; Stochastic Model; EOQ

\section{Introduction}

Timely provision of demands for goods has turned logistics and inventory operations into delicate undertakings for every industrial organizations. The capital invested in inventory stocks holds a great share in every economic sector. This huge capital also amounts for a great share of GDP. Inventory management activities necessitate considering inventory provision and maintenance processes as an integrated system and not as separate operational components ${ }^{2}$. The main objective of inventory planning and control is to adopt the best reordering and inventory maintenance policies by analyzing costs and conditions ${ }^{10}$. Inventory control is an operation that ensures required organizational items are delivered to the respective operational segment (manufacturing, distribution, sales, engineering, etc.) with regards to time, place, quantity, quality and $\operatorname{cost}^{9}$. The inventory includes raw materials, semi-finished materials, spare parts and products, the correct management of which would bring about an efficient work flow. Moreover, inventories play a determining role in creating more reliability, more robust planning and more endurance against changes ${ }^{14}$. In this study, stocks are studied under the conditions that more discounts would be given for more purchased quantities. Additionally, it is assumed that the system should not face inventory shortage since it would incur high costs on the system. This model is intended for Deteriorateable products, i.e. might become unfashionable or wasted and usable.

\section{Literature Review}

Production and inventory control includes planning and controlling for material flow and production operations. Materials are those items which are system inputs (raw materials and parts), are flowing in the production line (semi-finished products), and are system outputs (finished products). In other words, production and

${ }^{*}$ Author for correspondence 
inventory control is defined as maintaining items in desirable conditions to meet customer needs in a timely fashion with minimized system costs $^{10}$.

When an organization is out of stock and fails to meet customer demands, it will face stock shortage costs ${ }^{3}$. If available inventory is lower than customer demands, then there will be customer attrition ${ }^{9}$.

Usually large purchase orders are offered with a discount, therefore, encouraging more purchases. Accordingly, organizations should seek sales quantities that would minimize total costs of purchase, maintenance and ordering, despite discounts ${ }^{11}$. There are usually two kinds of discounts: general and special. The former is only studied in this paper. During stock ordering and procurement under general discount conditions, stores quote their prices in different quantity ranges, where the price of each range includes the whole order ${ }^{8}$.

The higher the economic value of a reorder, the higher the maintenance costs. Besides the maintenance costs, there is another cost called deterioration costs. deterioration can be defined as spoiling, damages, or becoming unfashionable. For example, in a production line, if the production equipment or the final product is changed, the warehouse stocks would become useless, therefore the purchase cost of the current inventory will be regarded as the deterioration cost $^{8}$.

Guchhait $^{7}$ Multi-item inventory model of breakable items with stock-dependent under stock and time dependent breakability rate. Here a multi-item inventory model of breakable items is developed, where demands of the items are stock dependent, breakability rates increase linearly with stock and nonlinearly with time ${ }^{7} . \operatorname{Lin}^{12}$ in an article A stochastic periodic review integrated inventory model involving defective items, backorder price discount, and variable lead time. The purpose of this article is to investigate a stochastic integrated supplier-retailer inventory problem. The model analyzed in this article explores the problem of the protection interval, the backorder price discount, the lead time, and the numbers of shipments from the supplier to the retailer in one production run as control variables to widen applications for an integrated periodic review inventory model ${ }^{13}$. Glock ${ }^{6}$ in an article Lead time reduction strategies in a single-vendor-singlebuyer integrated inventory model with lot size-dependent lead times and stochastic demand. This paper studies alternative methods for reducing lead time and their impact on the safety stock and the expected total costs of a (Q,s) continuous review inventory control system ${ }^{6}$. Chakrabortty ${ }^{4}$ in an article Intuitionistic fuzzy optimization technique for Pareto optimal solution of manufacturing inventory models with shortages. This paper discusses a manufacturing inventory model with shortages where carrying cost, shortage cost, setup cost and demand quantity are considered as fuzzy numbers ${ }^{4}$. Ghiami ${ }^{5}$ in an article A two-echelon inventory model for a deteriorating item with stock-dependent demand, partial backlogging and capacity constraints. This study investigates a two-echelon supply chain model for deteriorating inventory in which the retailer's warehouse has a limited capacity ${ }^{5}$. Sazver ${ }^{15}$ a replenishment policy for perishable products with nonlinear holding cost under stochastic supply lead time. In this study, we develop an inventory model for a main class of deteriorating items, namely perishable products, under stochastic lead time assumption ${ }^{15}$. Lee ${ }^{12}$ in an article An optimal policy for a single-vendor single-buyer integrated production-distribution model with both deteriorating and defective items. This article develops an integrated production-distribution model to determine an optimal policy with both deteriorating and defective items under a single-vendor single-buyer system. The objective of this article is to maximize the supply chain profit and to find the optimal numbers of delivery after incorporating deterioration and defectiveness into one model ${ }^{12}$.

Tayal $^{16}$ in an article A multi item inventory model for deteriorating items with expiration date and allowable shortages. This article presents a multi item inventory model to optimize the unit time profit of inventory management for the products having an expiration date after which the product can not be sold ${ }^{16}$.

\section{Statement of the Problem}

Supply chain management, i.e. controlling over the raw materials to final customer domain, is essential for more or less every organization. Senior managers today appreciate the strategic significance of supply chain management. In industrial factories, the capital invested in the inventory is high. Moreover, controlling the capital put into raw materials, semi-finished products and final products can offer a great potential for improvement. Using scientific methods for inventory control can generate competitive advantages for companies ${ }^{1}$. In the classic EOQ model, all parameters are considered deterministic and with a fixedvalue. However, in our proposed model, purchase and maintenance costs are included along with discounts and probable deterioration costs. 


\section{Problem Modelling}

To propose the inventory model, parameters and variables are first introduced and the proposed model is then presented.

C : Cost of each order

D : Rate of demand (consumption rate per unit time)

h : Cost of maintenance (cost of maintaining one item per unit time)

$\mathrm{u} \quad$ : unit price of an item

$\mathrm{Q}=\mathrm{Q}_{\mathrm{w}}$ : Quantity of each reorder (Wilson's point)

$Q_{s} \quad$ : Negative inventory (shortage)

s : Cost of exposure to inventory shortage (cost induced by shortage of each unit item per unit time)

d : : Amount of undeterioration items

$\mathrm{P}(\mathrm{d}) \quad$ : stochastic of deterioration

TOC : Total Ordering Cost (total cost of ordering per unit time)

THC : Total Housing Cost (total cost of housing or storing per unit time)

TMC : Total Paid Cost for purchasing items per unit time

TDC : Total deterioration Cost (total deterioration, becoming unfashionable, per unit time)

TSC : Total Shortage Cost (total cost of exposure to shortage per unit time)

TIC : Total Inventory Cost (total cost of inventories per unit time)

\subsection{Modeling}

Industrial factories are faced with various inventory costs and they try to implement inventory control policies in one way or another to minimize total costs. Costs incurred to a system by inventory include ordering cost (Equation 2), housing cost (Equation 3), and procurement cost (Equation 4) (7).

$$
\begin{gathered}
Q_{w}=Q=\sqrt{\frac{2 C D}{h}} \\
T O C=C \times \frac{D}{Q} \\
T H C=h \times \frac{Q}{2}
\end{gathered}
$$

$$
\begin{gathered}
T M C=D \times u \\
T I C=T O C+T H C+T M C \\
T I C=C \times \frac{D}{Q}+h \times \frac{Q}{2}+D \times u
\end{gathered}
$$

In this study, an inventory model was studied under no shortage costs, because the shortage cost is infinitely high (Equation 6).

In the first assumption, there is a discount id offered on larger orders. The discount type in this case is general; that is, by purchasing a certain quantity, a discount is received on all items. Therefore, the purchase cost is calculated based on the ordered quantity. The administrative affairs and general costs of warehousing (like air conditioning, lighting, etc.) are common for all items, accordingly, the warehousing cost is also reduced, which we call it a discount as well ${ }^{8}$.

The second assumption of the studied problem is deterioration, for which a new cost is defined as deterioration cost. In this study, deterioration is stochastic (Equation 7). Since, in market predictions, it is possible to assert that a certain amount of materials would not perish until reordering, the mean amount of deteriorate items is considered. The total cost can be determined using Equation 8 and Equation 9.

$$
\begin{gathered}
T D C=\left(P(d) \times\left(\frac{Q-d}{2}\right) \times u\right) \\
T I C=T O C+T H C+T M C+T D C
\end{gathered}
$$

$T I C=\left(C \times \frac{D}{Q}\right)+\left(h \times \frac{Q}{2}\right)+(D \times u)+\left(P(d) \times\left(\frac{Q-d}{2}\right) \times u\right)$

With regards to Figure 1, in order to determine the economical reorder point, first, the TIC at Wilson's point and $Q_{u}$ points on the right of $Q_{w}, Q_{h}$ values on the left of $Q_{w}$, and the starting point of deteriorating (d) should be examined. Then the value of $\mathrm{Q}$ for which TIC would be minimum can be selected.

\section{Numerical Example}

The following prices and terms are quoted by a seller for a given commodity:

The total consumption of this item is estimated at 23000. The cost of each ordering is 7500 unit currency and 


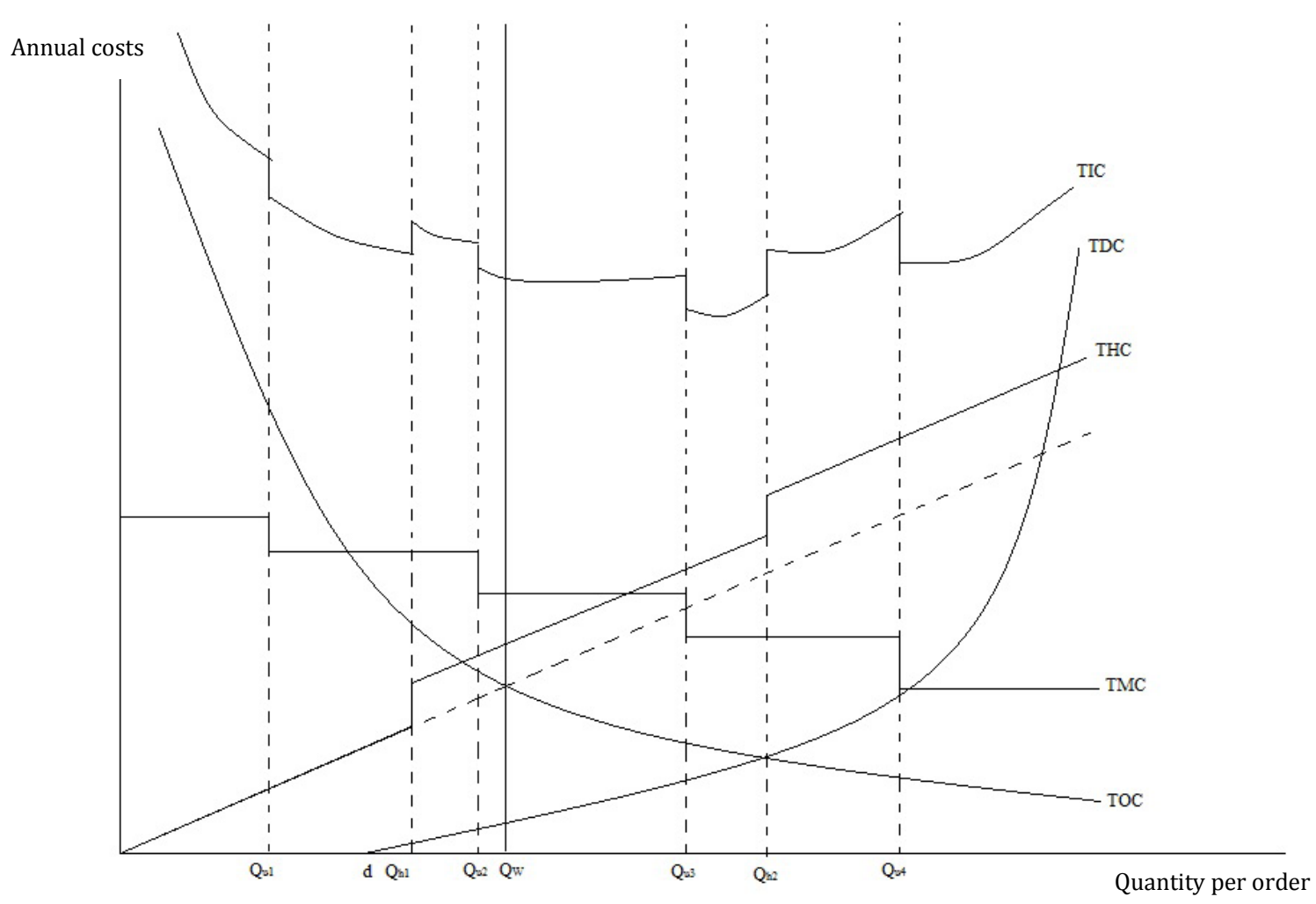

Figure 1. Annual costs for the quantity of each reorder (7).

Table 1. Item's unit price for different quantities

\begin{tabular}{lc}
\hline $\begin{array}{l}\text { Ordered quantity } \\
\text { (unit item) }\end{array}$ & $\begin{array}{c}\text { Price of unit item for } \\
\text { total ordered quantity }\end{array}$ \\
\hline 0 to 1999 & 5000 \\
2000 to 4999 & 4750 \\
5000 to 9999 & 4450 \\
10000 and more & 4125 \\
\hline
\end{tabular}

warehousing cost is 56 unit currency, which is discounted by 3 unit currency per unit item for each 5000 items or more. According to the predictions, 1700 non-perished items would remain in the warehouse and more than 1700 items would perish according to Poison's distribution. The economical quantity for each order is:

$$
D=23000, C=7500
$$

At first, we determined Wilson's point, provided that the warehousing cost is variable. Therefore, we examined Wilson's point for each price range:

$$
Q_{0-1999}=\sqrt{\frac{2 C D}{h}}=\sqrt{\frac{2 \times 7500 \times 23000}{56}}=2482.07 \cong 2482
$$

Unacceptable
$Q_{2000-4999}=\sqrt{\frac{2 C D}{h}}=\sqrt{\frac{2 \times 7500 \times 23000}{56}}=2482.07 \cong 2482$

Acceptable

$Q_{5000-9999}=\sqrt{\frac{2 C D}{h}}=\sqrt{\frac{2 \times 7500 \times 23000}{53}}=2551.36 \cong 2551$

Unacceptable

$Q_{>10000}=\sqrt{\frac{2 C D}{h}}=\sqrt{\frac{2 \times 7500 \times 23000}{50}}=2626.78 \cong 2627$

Unacceptable

Since only the order quantity of 2482 units is in the acceptable range, the economical point is 2482 .

Next, the stochastic of deterioration is determined. Since the deterioration function is Poison's, its stochastic is determined as follows:

$$
\begin{gathered}
P(d=1700)=0 \\
P(1700<d \leq 2000)=0.05 \\
P(1700<d \leq 2482)=0.1
\end{gathered}
$$




$$
\begin{gathered}
P(1700<d \leq 5000)=0.3 \\
P(1700<d \leq 10000)=0.6
\end{gathered}
$$

For the third step, the value of TIC from Equation 8 was examined for each Wilson's value and values on the right of Wilson's. Then, the values on the left of Wilson's point to the point deterioration were also examined.

$$
\begin{aligned}
T I C= & T O C+T H C+T M C+T D C \\
T I C= & \left.C \times \frac{D}{Q}\right)+\left(h \times \frac{Q}{2}\right)+(D \times u)+\left(P(d) \times\left(\frac{Q-d}{2}\right) \times u\right) \\
T I C_{w}= & \left(7500 \times \frac{23000}{2482}\right)+\left(56 \times \frac{2482}{2}\right)+(23000 \times 4750) \\
& +\left(P(1700<d \leq 1700) \times\left(\frac{2482-1700}{2}\right) \times 4750\right) \\
T I C_{w}= & 109574721
\end{aligned}
$$

TIC was then examined for 5000 unit items:

$$
\begin{aligned}
T I C_{5000}= & \left(7500 \times \frac{23000}{5000}\right)+\left(53 \times \frac{5000}{2}\right)+(23000 \times 4450) \\
& +\left(P(1700<d \leq 5000) \times\left(\frac{5000-1700}{2}\right) \times 4450\right) \\
T I C_{5000}= & 103251250
\end{aligned}
$$

Then for 10000 unit items:

$$
\begin{aligned}
T I C_{10000}= & \left(7500 \times \frac{23000}{10000}\right)+\left(50 \times \frac{10000}{2}\right)+(23000 \times 4125) \\
& +\left(P(1700<d \leq 10000) \times\left(\frac{10000-1700}{2}\right) \times 4125\right) \\
T I C_{10000}= & 105413500
\end{aligned}
$$

Finally, TIC was determined for 1700 unit items:

$$
\begin{aligned}
T I C_{1700}= & \left(7500 \times \frac{23000}{1700}\right)+\left(56 \times \frac{1700}{2}\right)+(23000 \times 5000) \\
& +\left(P(d=1700) \times\left(\frac{1700-1700}{2}\right) \times 5000\right) \\
T I C_{1700}= & 115149070
\end{aligned}
$$

Comparing the determined TICs showed that the total cost would be minimized for 5000 unit items.

\section{Discussion and Conclusion}

The most important and fundamental responsibilities of every industrial unit are inventory planning and control. In this regard, the responsibility of production and inventory control personnel is to adopt the best policies that minimize costs, while considering all factors. In this study, an inventory model under probable deterioration and discount conditions was developed, through which the economical quantity of orders can be determined. Results revealed that, under study conditions, the amount of deteriorative items and therefore the final costs increase with larger order quantities. However, on the other hand, higher discounts are offered for larger order quantities. Accordingly, selecting the best reorder point can reduce incurred costs to an organization.

In addition to stochastic deterioration, future research may include stochastic consumption and/or receiving rates in the inventory model, or examine this model while all three are stochastic. Furthermore, the inventory model can be investigated with multiple products.

\section{References}

1. Axsäter S. Inventory Control: Springer; 2007.

2. Banks J, Fabrycky WJ. Procurement and inventory systems analysis: Prentice-Hall; 1987.

3. Behzadian M. Inventory planning and control (1). 1, editor. Amol: nashr shomal paydar; 2005. 1-112 p.

4. Chakrabortty S, Pal M, Nayak PK. Intuitionistic fuzzy optimization technique for Pareto optimal solution of manufacturing inventory models with shortages. European Journal of Operational Research. 2013.

5. Ghiami Y, Williams T, Wu Y. A two-echelon inventory model for a deteriorating item with stock-dependent demand, partial backlogging and capacity constraints. European Journal of Operational Research. 2013.

6. Glock $\mathrm{CH}$. Lead time reduction strategies in a singlevendor-single-buyer integrated inventory model with lot size-dependent lead times and stochastic demand. International Journal of Production Economics. 2012; 136(1):37-44.

7. Guchhait P, Maiti MK, Maiti M. Multi-item inventory model of breakable items with stock-dependent demand under stock and time dependent breakability rate. Computers \& Industrial Engineering. 2010; 59(4):911-20.

8. Haj shirmohammadi A. principles of production and inventory planning and control. Isfahan: arkan danesh; 2008. 27-377 p. 
9. Hosseini baharanchi R. Order planning and control of production and inventory. 1, editor. Tehran: Jahan jam jam; 2002. 1-137 p.

10. Javadian n, Naij haghighi J. Inventory planning and control. 1, editor. Babol: Olomrayaneh; 2010. 9-220 p.

11. Khademi Zarea H. Inventory control. 1, editor. tehran: Soroush danesh; 2004.

12. Lee S, Kim D. An optimal policy for a single-vendor singlebuyer integrated production-distribution model with both deteriorating and defective items. International Journal of Production Economics. 2014; 147:161-70.

13. Lin Y-J. A stochastic periodic review integrated inventory model involving defective items, backorder price discount, and variable lead time. 4OR. 2010; 8(3):281-97.
14. Muller M. Essentials of Inventory Management: AMACOM; 2011.

15. Sazvar Z, Baboli A, Jokar MRA. A replenishment policy for perishable products with non-linear holding cost under stochastic supply lead time. The International Journal of Advanced Manufacturing Technology. 2013; 64(5-8):1087-98.

16. Tayal S, Singh S, Sharma R. Multi Item Inventory Model for Deteriorating Items with Expiration Date and Allowable Shortages. Indian Journal of Science and Technology. 2014; 7(4):463-71. 